高分子圇女集 (Kobunshi Ronbunshu), Vol. 43, No. 1, pp. 15-18 (Jan., 1986)

\title{
フェロセンを結合したポリ(ビニルアミン)-銅(II) 混合金属錯体の合成*
}

\author{
黑瀬 榇男*1 ・楠 幹夫*1 ・英 謙二*1 ・增田 说子*1 $・$ 白井 汪芳*1 $・$ 北條 舒正*2
}

(受付 1985 年 8 月 8 日・变查終了 1985 年 8 月 28 日)

\begin{abstract}
要 旨 ポリビニルアミン（以下 PVAm と略す）に，種ヶの異なった含有串のフェロセン (Fc) を担持させた Fc-PVAm を合成した。フェロセン $7.6 \mathrm{~mol} \%$ を担持させた Fc-PVAm 系は, つ セトンと水の混合溶夜 (1:1) に可溶である。我々は，Cu(II) イオンと,この Fc-PVAm 系の錯生 成を， pH 滴定，电子スペクトルなどにより榆时した。その結果，Fc-PVAm 系で，フリーの丁ミ

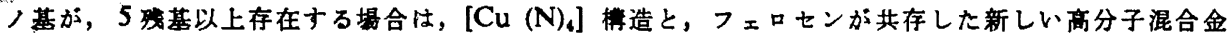
属錯体が生成することがわかった。
\end{abstract}

\section{1 緒 曹}

混合原子価錯体及び，異㯖金属混合型錯体は，触媒， 磁性，䉓気，光電気化学などの分野で與味深い举動を示 すことから，最近非常な関心を集めている，しかし，有 機高分子系での研究は，ほとんどなされていない.

我々の研究室では，混合原子価型1) 3) 及び異種金属混 合型4) の高分子金属錯体の合成と機能について一連の研 究を行っている.

本研究では，㻴同士の接近による $\mathrm{Fe}-\mathrm{Fe}$ 間の相互作 用発現や，環への他の金属イオンの接近が高分子内で起 こると磁気, 光機能など興味ある展開の可能性が考えら れる.フェロセン (Fc) を, ポりビニルフミン (PVAm) に，共有結合で導入し，更に残ったアミノ基に $\mathrm{Cu}$ (II) イオンを配位した，新しい高分子混合金属錯体の合成を 試みた。これは，高度な機能をねらった高分子多核錯体 の基礎的研究であり，どのよな混合金属錯体が得られ るかを知ることが目的である.これらの結果について報 告する.

\section{2 实験}

\section{1 試料}

ボリビニルフミン (PVAm) の合成に用いた，フタル イミド, 無水酢酸, 酢酸ナトリウム, エチレンクロライ ト，その他は，市販特級品を，そのまま用いた， $N, N^{\prime}$ ジチルホルムフミド (DMF) は, 市販品を脱水し, 常

* 本報を「高分子多核金虽錯体 第 6 報」とする。

*1 伤州大学縺維学部機能高分子学科（⿶386 上田市常 田 3-15-1)

*2 俉州大学 (亚390 松本市地 3-1-1)
法により，蒸留して使用したまたフコェセンモノカ ルボン酸クロリドの合成に用いたフェロセン, ジフェニ ルカーハミ゙ル酸クロリド，その他の試薬は，市販特級品 を、そのまま用いた。

\section{2 ポリビニルアミン (PVAm) の合成}

PVAm の合成は, D. D. Reynolds らの方法 ${ }^{\text {) }}$ を用 いて行った.

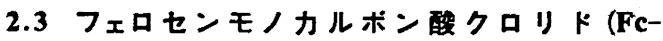
COCI) の合成

Fc-COCl の合成は, William, F.L. らの方法" ${ }^{6)}$ より 行った。

2.4 フェロセンを担持した Fc-PVAm の合成
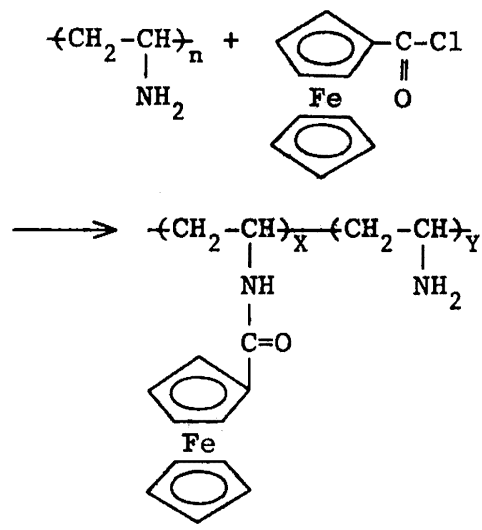

ポリビニルアミン $0.5 \mathrm{~g}$ をワロホルムで膨潤させ, フェロセンモノカルボン酸クロリドを加えて 2 3 時間 室温でかくはん後,クロロホルムを除去し, 希塩酸 $25 \mathrm{ml}$ を加えて酸性にし，浱縮後ェーテルで洗浄し合成した。 
Table 1. Contents of Fc attached to poly(vinylamine) and their solubilitya)

\begin{tabular}{ccccc}
\hline \hline No. & Contents of $\mathrm{Fc} \mathrm{in} \mathrm{mol} \%$ & $\mathrm{CH}_{8} \mathrm{COCH}_{3}: \mathrm{H}_{2} \mathrm{O}(1: 1)$ & $\mathrm{CH}_{3} \mathrm{COCH}_{3}$ & $\mathrm{H}_{2} \mathrm{O}$ \\
\hline 1 & 0.7 & 0 & 0 & $\circ$ \\
2 & 7.6 & 0 & $\Delta$ & $\Delta$ \\
3 & 14.0 & $\Delta$ & $\Delta$ & $\times$ \\
4 & 19.6 & $\Delta$ & $\Delta$ & $\times$ \\
5 & 21.0 & $\Delta$ & $\Delta$ & $\times$ \\
\hline
\end{tabular}

ə) $O$, soluble; $\lrcorner$, swell; $\times$, insoluble.

この场合，フェロセンの仕込み量を变化させ，種々の フェロセン含有贵の PVAm を合成した. Table 1 にフ エロセン含有量と溶解性を示した. Fc 含有量 7.6 mol\% の Fc-PVAm は,アセトンと水の混合溶液に可 溶であるか，Fc 含有量が $14.0 \mathrm{~mol} \%$ 以上になると， 不溶になった，そこで，本報告では，Fc 含有量か， 7.6 mol\% の Fc-PVAm を使用し，以後の実験を行った。

2.5 フェロセンを担持したボリヒニルアミンー銿 (II) 錯体 (Cu(II)-Fc-PVAm) の生成

2.4 で合成した $9.20 \times 10^{-3} \mathrm{M}$ の Fc-PVAm（アセ卜 ン・水混合）溶液 $5 \mathrm{ml}, \quad 2.0 \times 10^{-2} \mathrm{M}$ の硝酸銅水溶液 $0.47 \mathrm{ml}, 1 \mathrm{M}$ の $\mathrm{KNO}_{3}$ を $1 \mathrm{ml}$ 混合し、これに $0.1 \mathrm{M}$ の $\mathrm{KOH}$ を, $0 \sim 1.0 \mathrm{~m} l$ まで $0.1 \mathrm{~m} l$ ずつ增加させなが ら加えてゆき，最後に純水で全其を $10 \mathrm{ml}$ にした。こ れを, $25^{\circ} \mathrm{C}$ の佰温槽中で約 24 時間平衡に保って錯体を 生成させた，更に，Cu(II) イオン䈨度を变化させた系も 同様にして調製した。

\section{$2.6 \mathrm{pH}$ 測定}

2.5 で調製した試料の pH を, ORION RESEARCH model $701 \mathrm{~A}$ 型 $\mathrm{pH}$ 測定計により測定した.

\section{7 子スペクトル・ESR スベクトルの即定}

2.5 で調製した試料の可視スペクトルは，(株) 日本分 光製 JASCO ・ UVIDEC-505 型自己分光光度計により, 電子スピン共鳴 (ESR) スペクトルは，Varian E-102 型 ESR 装圈により測定した.

\subsection{Fc-PVAm の Fc 緗入事の定量}

2.4 で合成した Fc-PVAm の Fc 尊入率は， $0-7 ェ$ ナンスロリン法りによる電子スベクトル及び，日製産業

(株) 製, 日立 170-70 型ゼーマン原子吸光分光光度計に より，定量した。

\section{3 結果と考察}

Fig. 1 は, Fc-PVAm (a) 及び, フリーのアミノ基 と $\mathrm{Cu}$ (II) イオンのモル比 $\left(T_{\mathrm{Ca}^{2}}{ }^{2+} / T_{\mathrm{BL}}\right) 0.2$ で $\mathrm{Cu}$ (II) イオンを混合した系 $\mathrm{Cu}(\mathrm{II})-\mathrm{Fc}-\mathrm{PVAm}$ 系 (b) の pH 滴定曲線である. $\mathrm{Cu}(\mathrm{II})$ イオンを含む系 (b) は，(a)

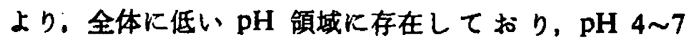
付近に衡領城が見られ，この領域での $\mathrm{Cu}(\mathrm{II})$ 錯体の

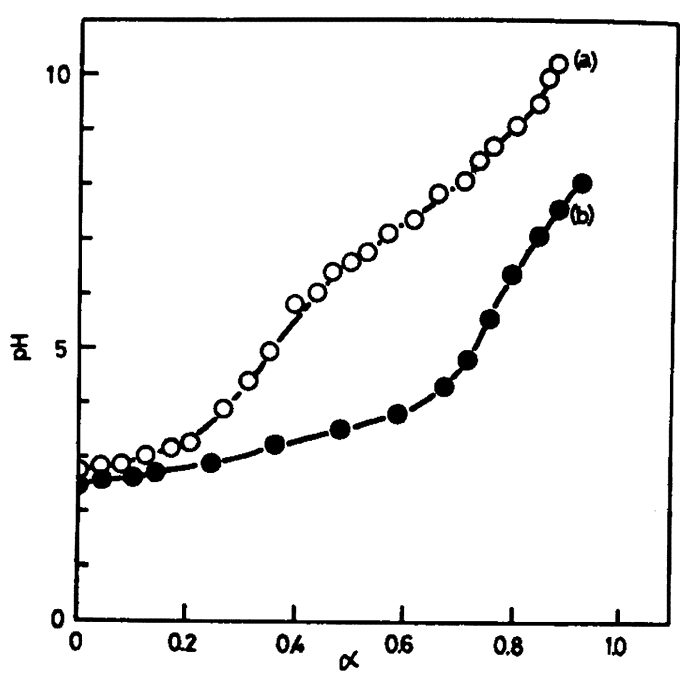

Fig. 1. Potentiometric titrations of Fc-PVAm (a) and $\mathrm{Cu}(\mathrm{II})-\mathrm{Fc}-\mathrm{PVAm}$ (b) systems.

$T_{\mathrm{Cu}^{2+}}{ }^{2+} T_{\mathrm{HL}}=0.2, \mu=0.1\left(\mathrm{KNO}_{3}\right), 25^{\circ} \mathrm{C}$ $\alpha=\frac{\text { The concentration of aded } \mathrm{KOH}}{\text { Total molar concentration of }-\mathrm{NH}_{2}}$

生成が考えられる。この埸合, Cu(II)-Fc-PVAm (b) 系で消费された $\mathrm{OH}^{-}$の贵を $\mathrm{Cu}(\mathrm{II})$ イオン 1 原子当たり に計算すると，Cu(II) イオン 1 原子について約 4 個の OH- が消费されている．このことより，Cu(II) イオン 1 原子につき約 4 個の $\mathrm{H}^{+}$が放出されており，次の平街 が考えられる.

$$
\text { 4- } \mathrm{NH}_{3} \mathrm{Cl}+\mathrm{Cu}^{2+} \rightleftharpoons\left[\mathrm{Cu}\left(\mathrm{NH}_{2}\right)_{4}\right]^{2+}+4 \mathrm{HCl}
$$

各種 $\mathrm{pH} て ゙$, 生成された $\mathrm{Cu}(\mathrm{II})-\mathrm{Fc}-\mathrm{PVAm}$ 系の電 子スペクトルより求めた d-d 吸収帯の $\lambda_{\max }$ と $D_{\max }$ 值を $\mathrm{pH}$ に対してプロットしたのが Fig. 2 である. $D_{\max }$ 値は， $\mathrm{pH} か ゙ 4.6$ 付近まで上界し， $\mathrm{pH}>4.6$ で 一定となる． $\mathrm{pH}>7$ では，錯体の不溶化が起こり $D_{\mathrm{mux}}$ 值は，見掛け上，上早する。，一方 $\lambda_{\max }$ 值は， pH 2 4.6 付近まで低波長シフトを繶け，pH>4.6 で一定波長 $580 \mathrm{~nm}(\log \varepsilon=2.1)$ に達する。 これより，FC-PVAm の $-\mathrm{NH}_{2}$ 残基への $\mathrm{Cu}(\mathrm{II})$ イオンの配位は, $\mathrm{pH} \simeq 4.6$ 


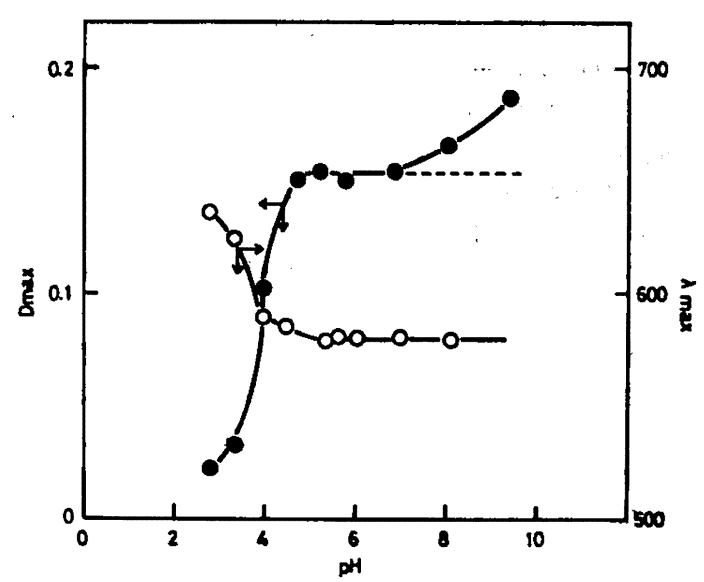

Fig. 2. $\mathrm{pH}$ dependence of $D_{\max }$ and $\lambda_{\max }$ for $\mathrm{Cu}(\mathrm{II})-\mathrm{Fc}-\mathrm{PVAm}$ systems in solution. [Fc-PVAm] $=9.20 \times 10^{-3} \mathrm{~mol} / l, \quad 25^{\circ} \mathrm{C}, \quad \mu=0.1$ $\left(\mathrm{KNO}_{3}\right)$

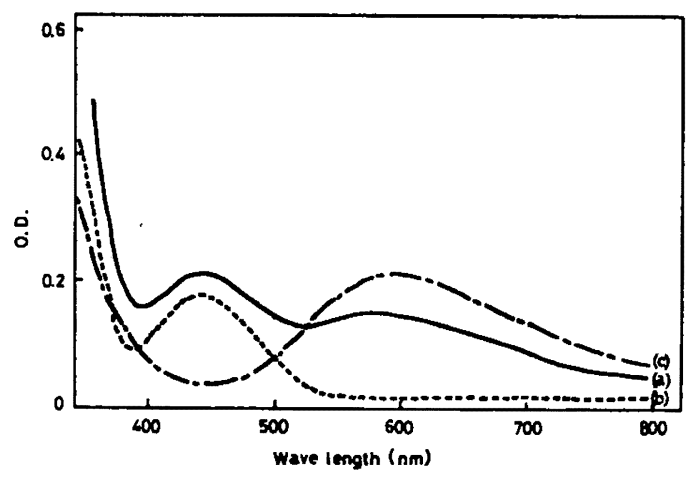

Fig. 3. Electronic spectra of $\mathrm{Cu}(\mathrm{II})-\mathrm{Fc}-\mathrm{PVAm}$ (a), Fc-PVAm (b) and Cu(II)-PVAm (c) systems. (a), (b): [Fc-PVAm] $=9.20 \times 10^{-8} \mathrm{~mol} / l$, (a): $[\mathrm{Cu}$ (II) $]=1.04 \times 10^{-4} \mathrm{~mol} / /$ (c): $[\mathrm{Cu}(\mathrm{II})]=1.59 \times 10^{-3}$ $\mathrm{mol} / \mathrm{l}$

で完了することがわかる. Fc を含まない Cu(II)PVAm 系の d-d 吸収带は, $595 \mathrm{~nm}(\log \varepsilon=2.2)$ であ $\eta$, 混合系 $\mathrm{Cu}(\mathrm{II})-\mathrm{Fc}-\mathrm{PVAm}$ の $\lambda_{\max }$ 值, $\varepsilon$ 値と若 千の変化はあるが, 混合禾です,フリーの VAm 残基 と $\left[\mathrm{Cu}\left(\mathrm{N}_{4}\right)\right]^{2+}$ 型㭗造が形成されるるのと思われる.

Fig. 3 は, Fc-PVAm の - $\mathrm{NH}_{2}$ 残基へ $\mathrm{Cu}(\mathrm{II})$ イ オンを配位させた场合の典型的な奄子スペクトル (a) を, Fc-PVAm 系 (b) 及び Cu(II)-PVAm 系 (c) と 比较して示している，Cu(II)-Fc-PVAm 系 (a) では, Fc に基づく特性吸収 $430 \mathrm{~nm}$ と, $580 \mathrm{~nm}$ の [Cu(II)$\left.\mathrm{N}_{4}\right]^{2+}$ 型の d-d吸收带が現れている.

次に, Cu(II)-Fc-PVAm 混合系で, Cu(II) イオン

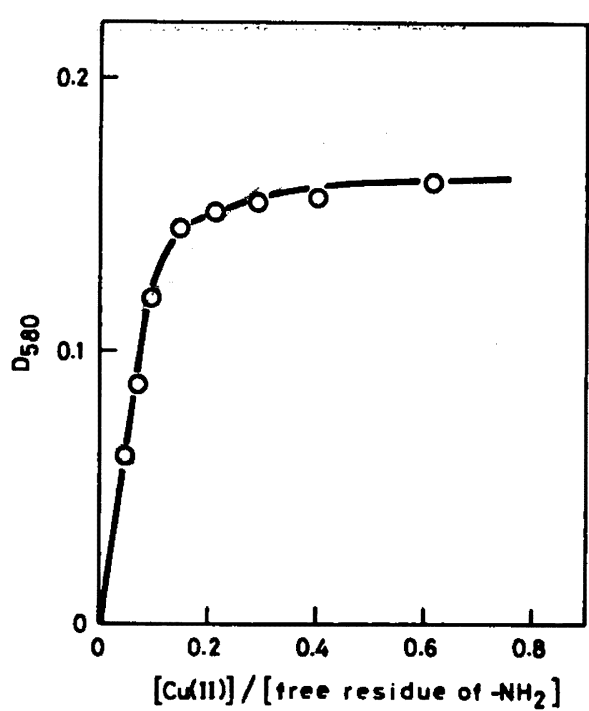

Fig. 4. Relationship between $D_{580}$ and $[\mathrm{Cu}(\mathrm{II})] /$ [free residue of $-\mathrm{NH}_{2}$ ] in $\mathrm{Cu}(\mathrm{II})-\mathrm{Fc}-\mathrm{PVAm}$ systems in solution.

[Fc-PVAm] $=9.20 \times 10^{-3} \mathrm{~mol} / l, \quad 25^{\circ} \mathrm{C}, \quad \mu=0.1$ $\left(\mathrm{KNO}_{3}\right)$

灌度とフリーのフミ，基とのモル比 $\left(T_{\mathrm{Ca}}{ }^{2+} / T_{\mathrm{HL}}\right)$ と $D_{580}$ の関係をプロットしたのが Fig. 4 である. $T_{\mathrm{Cu}^{2+}}$ $T_{\mathrm{HL}}$ 値 0.2 付近で, $D_{880}$ 值は一定に逵する。これは, $\mathrm{Cu}$ (II) イオン 1 原子当たり， 5 個のフリー, $-\mathrm{NH}_{2}$ が 存在するとき $\left[\mathrm{Cu}-\left(\mathrm{N}_{4}\right)\right]^{2+}$ 型棈造が飽和に達することを 示している. それ以上では，立体障害の影䡬が考えられ る.

$430 \mathrm{~nm}$ の Fc に基づく吸収及び $\left[\mathrm{Cu}(\mathrm{II})-\mathrm{N}_{4}\right]^{2+}$ 型

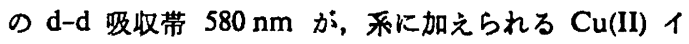
オン注度の增加により，どように変化するか次に調べ た。

Cu(II)-Fc-PVAm 混合系において，Cu(II) イォン の錯生成が完了する pH 4.6 で Cu(II) イオンの渡度 を変化させた. Cu(II)-Fc-PVAm 混合系の，Fc の特

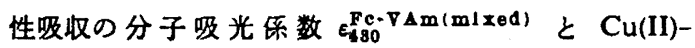
VAm 錯体部の分子吸光保数 $\varepsilon_{5 B 0}^{C u(I I)-V \Delta \mathrm{m}(\mathrm{mlxed})}$ は, 次式 (1)，(2) より求められる.

$$
\begin{aligned}
& \varepsilon_{580}^{\mathrm{Cu}(\mathrm{II})-\nabla \Delta \mathrm{m}(\mathrm{mlred})}=D_{580} / C_{\mathrm{Cu}^{2+}}{ }^{2+} \varepsilon_{580}^{\mathrm{Fc}} \\
& \varepsilon_{430}^{\mathrm{Fe}-\nabla \Delta \mathrm{m}(\mathrm{ml} 1 \mathrm{xed})}=D_{430} / C_{\nabla_{0}}-\varepsilon_{430}^{\mathrm{Cu}(\mathrm{II}) \cdot \nabla \mathrm{Am}} \\
& \text { (C: 濃度 }=\mathrm{mol} / \mathrm{l} \text { ) }
\end{aligned}
$$

ここで, $\varepsilon_{580}^{F c}, \varepsilon_{430}^{\mathrm{Cu}(I I)-\nabla A m}$ は, Fc-PVAm 系, Cu(II)PVAm 系それぞれの分子吸光係数であり， $D_{580} ， D_{430}$ は，混合系の見掛けの吸光度を示している.

Fig. 5 は, 混合系の $\varepsilon_{480}^{\mathrm{Fc} \cdot \mathrm{VAm}(\mathrm{m} l \mathrm{xed})}$ と 


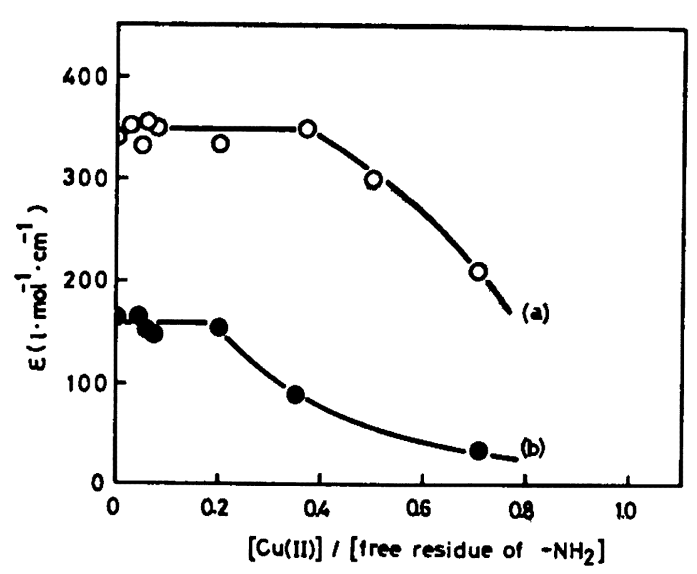

Fig. 5. [Cu (II)]/[free residue of $\left.-\mathrm{NH}_{2}\right]$ dependence of $\varepsilon_{480}^{\mathrm{Fc}-\nabla \Delta \mathrm{m}(\mathrm{mlxed})}$ and $\varepsilon_{\mathrm{b80}}^{\mathrm{Cu}(\mathrm{II})-\nabla \Delta \mathrm{m}(\mathrm{ml} / \mathrm{xed})}$ for $\mathrm{Cu}$ (II)-Fc-PVAm systems in solution.

[Fc-PVAm] $=9.20 \times 10^{-3} \mathrm{~mol} / l, \quad 15^{\circ} \mathrm{C}, \quad \mu=0.1$ (KNOs)

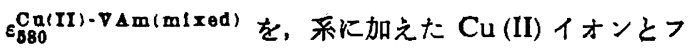

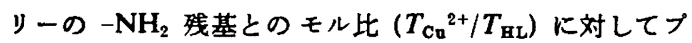
ロットした図である.この四より， $\varepsilon_{430}^{\mathrm{Fc}-\nabla \mathrm{Am}(\mathrm{m} 1 \mathrm{xed})}$ は, $T_{\mathrm{Cr}^{2+}}{ }^{2+} T_{\mathrm{HL}}=0.35$, PVAm 䄪 2.8 個に 1 個の $\mathrm{Cu}^{2+}$ イ オンを加えた点まで変化しないが，更に多豆の $\mathrm{Cu}^{2+}$ イ オンを加えると，便端に小さな値となり，フェロセンが 变化することが予想される. $e_{880}^{\mathrm{Cu}(I I)-V \Delta m(m 1 x e d)}$ の值 は, PVAm 約 5 残基に 1 個の $\mathrm{Cu}^{2+}$ イオンが存在する までは，ほとんど変化しないが，それ以上では，高分子
}

鎖の立体障害などから著しく， $\varepsilon$ 做が減少している。 た, pH 7.0, $-120^{\circ} \mathrm{C}$ に抽る, $\mathrm{Cu}(\mathrm{II})$-PVAm 系と, $\mathrm{Cu}(\mathrm{II})-\mathrm{Fc}-\mathrm{PVAm}$ 混合系の, ESR スペクトルより, $g_{\perp}$ 值は，それぞれ 2.098，2.096 とほぼ一政しており， Cu(II)-Fc-PVAm 混合系の, Cu(II) イオンは, Cu(II)PVAm 系と同様の配位棰造を有することがわかった.

以上の結果より，Fcを $7.6 \mathrm{~mol} \%$ 含むPVAm 手で

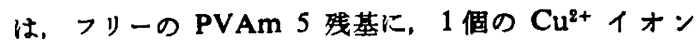
が配位しても，フェロセン (Fc) と $\left[\mathrm{Cu}(\mathrm{II})-\mathrm{N}_{4}\right]^{2+}$ は, 相互作用しないで共存することが明らかになった。しか し, 極端に系の $\mathrm{Cu}(\mathrm{II})$ イオン灌度を增加させると，Fc 及び $\left[\mathrm{Cu}(\mathrm{II})-\mathrm{N}_{4}\right]^{2+}$ の配位構造は, 变化することがわか った.

\section{文部}

1) T. Koyama, A. Kurose, K. Hanabusa, E. Masuda, H. Shirai, T. Hayakama, and $\mathbf{N}$. Hojo, Bull. Chem. Soc. Jpn., in press.

2) T. Koyama, A. Kurose, E. Masuda, K. Hanabusa, H. Shirai, T. Hayakawa, and N. Hojo, Makromol. Chem., in press.

3) T. Koyama, R. Hayashi, A. Kurose, K. Hanabusa, E. Masuda, H. Shirai, T. Hayakawa and N. Hojo, in preparation.

4) 白井汪芳, 仁尾量, 黒激新男, 林員男, 北 保舒正，日本化学会誌，1，117 (1978).

5) D.D. Reynolds and W.O. Kenyon, J. Org. Chem., 1, 911 (1947).

6) F.L. William and E. Robert, J. Am. Chem. Soc., 82, 1577 (1960).

7) 日本分析化学会缘，“分析化学便筧”，丸善，東 京 $(1981)$, p. 99.

\section{Synthesis of Poly(vinylamine) to Attached Ferrocene Copper (II) Mixed Metal Complexes}

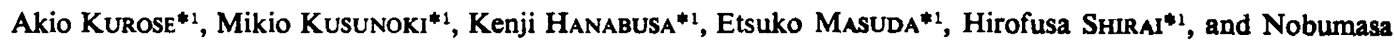
HoJo*2

*1Department of Functional Polymer Science, Faculty of Textle Science and Technology, Shinsku University (15-1, Tokida 3-chome, Ueda, 386 Japan)

*2Shishu University (1-1, Asahi 3-chome. Matsumoto, 390 Japan)

The synthsis of ferrocene-poly(vinylamine) (Fc-PVAm) complex was carried out under various contents of ferrocene. The Fc-PVAm (content of $\mathrm{Fc}=7.6 \mathrm{~mol} \%$ ) complex was dissolved in mixed solvents of acetone and aqueous solution, and was investigated using potentimetory, visible spectroscopy, and others. These experiments indicated that new mixed metal complexes having both $\left[\mathrm{Cu}\left(\mathrm{N}_{4}\right]\right.$ and $\mathrm{Fc}$ structures were formed when the ratio of free amio residue to copper ion was larger than 5 .

KEY WORDS Ferrocene / Poly(vinylamine) / Ferrocene-Poly(vinylamine) Complex / Complexation / Mixed Metal Complexes /

(Received August 8, 1985 : Accepted August 28, 1985)

[Kobunshi Ronbunshu, 43 (1), 15-18 (1986)] 